\author{
식품충분성과 다양성의 개인간 및 지역사회 관련 요인: \\ 2017년 지역사회건강조사 자료 분석 \\ 홍 지 연 ${ }^{1)}$ - 현 태 선 ${ }^{2)}$ \\ 1)충북대학교 식품영양학과, 박사과정생, ${ }^{2) ㅊ ㅜ ㅇ ㅂ ㅜ ㄱ ㄷ ㅐ ㅎ ㅏ ㄱ ㄱ ㅛ ~ ㅅ ㅣ ㄱ ㅍ ㅜ ㅁ ㅇ ㅕ ㅇ ㅇ ㅑ ㅇ ㅎ ㅏ ㄱ ㄱ ㅘ, ~ ㄱ ㅛ ㅅ ㅜ ~}$
}

\title{
Interpersonal and Community Factors Related to Food Sufficiency and Variety: Analysis of Data from the 2017 Community Health Survey
}

\author{
Jiyoun Hong ${ }^{1)}$ Taisun Hyun ${ }^{2 \dagger}$ \\ ${ }^{1)}$ Doctoral student, Department of Food and Nutrition, Chungbuk National University, Cheongju, Korea \\ ${ }^{2)}$ Professor, Department of Food and Nutrition, Chungbuk National University, Cheongju, Korea
}

\section{Corresponding author Taisun Hyun \\ Department of Food and Nutrition, Chungbuk National University, Cheongju, Chungbuk, 28644, Korea \\ Tel: (043) 261-2790 \\ Fax: (043) 267-2742 \\ E-mail: taisun@cbnu.ac.kr \\ Acknowledgments \\ This study was supported by Korean Centers for Disease Control and Prevention Agency (research promotion project for investigation of causes and solutions of regional healh disparities)(No. ISSN 2733- 5488).}

Received: October 8, 2020

Revised: October 28, 2020

Accepted: October 28, 2020

\section{ABSTRACT}

Objectives: This study examined the personal, interpersonal and community factors related to food sufficiency and variety among Korean adults using data from the 2017 Community Health Survey.

Methods: A total of 228,310 adults aged $\geq 19$ years were classified into three groups: food sufficiency with variety, food sufficiency without variety and food insufficiency. Personal factors included sociodemographic characteristics, health behavior and health status. Interpersonal factors included social networking and social activities, and community factors included safety, natural environment, living environment, availability of public transportation and health care services. The association of food sufficiency and variety with interpersonal and community factors was assessed using multivariable logistic regression analyses.

Results: Of the total sample, the food-sufficiency-without-variety group and food insufficiency group accounted for $31.5 \%$ and $3.2 \%$, respectively. The sociodemographic factors associated with food insufficiency and non-variety were women, $\geq 65$ years of age, with low education level, low household income, unemployed, single, and living in areas of small population sizes. There were significant differences in health behavior and health status, interpersonal and community factors among the three groups. Multivariable logistic regression analyses conducted after adjusting for confounding factors showed that lack of social networking and social activities and lower satisfaction derived from community environments were associated with the risk of food insufficiency and non-variety.

Conclusions: Our results showed that interpersonal and community factors as well as personal factors were related to food sufficiency and variety. Therefore, public policies to help build social networks and participation in social activities, and improve community environment are needed together with food assistance to overcome the problems of food insufficiency and non-variety.

Korean J Community Nutr 25(5): 416 429, 2020

KEY WORDS food sufficiency, variety, interpersonal factors, community factors

This is an Open-Access article distributed under the terms of the Creative Commons Attribution Non-Commercial License (http:// creativecommons.org/licenses/by-nc/3.0) which permits unrestricted non-commercial use, distribution, and reproduction in any medium, provided the original work is properly cited. 


\section{서 론}

식품안정성 (food security)은 모든 구성원이 활기차고 건강한 삶을 유지하기 위하여 영양적으로 충분하고 안전한 식품을 사회적으로 수용 가능한 방법으로 항상 확보하고 있 는 상태'를 의미한다[1]. 식품안정성이 확보되지 못한 식품 불안정 (food insecurity)은 개인의 육체적, 정신적, 사회적 건강에 부정적인 영향을 미치게 되며, 삶의 질을 낮추게 되 므로 해결해야 할 사회적인 문제의 하나이다 $[2,3]$. 식품안 정성을 확보하는 것은 제 4 차 국민건강증진종합계획의 영양 분야 5 개 목표 중 하나로서, 식품안정성 확보가구 비율의 목 표치는 2020년까지 95\%를 달성하는 것이다 [4]. 2017년 국민건강영양조사에 따르면 경제적인 어려움으로 식품공급 이 부족한 식품불안정 가구는 우리나라 전체 가구의 약 $3.7 \%$ 로 2020년 목표치는 달성되었으나, 최하위 소득수준 가구 에서는 $11.8 \%$ 로 높게 나타났다 [5].

식품불안정의 가장 중요한 영향 요인은 소득이며, 그 외에 65세 이상, 여성, 낮은 교육수준, 농촌 지역 거주 등의 개인 적 특성과 1 인 가구, 독거노인 가구, 한부모 또는 조손가정 등의 가구 특성이 관련되는 것으로 알려져 있다 [6-8]. 식 품불안정 가구의 성인은 흡연, 운동부족 등 건강 위험 행동 의 경향이 높았고 [9-11], 식품안정성 가구의 성인에 비해 에너지 섭취량이 낮았으며, 식사횟수도 적어 영양상태가 불 량하였다 $[7,11]$. 또한 식품불안정은 당뇨, 고혈압, 비만, 심 혈관계 질환 등 만성질환의 유병과도 관련이 있는 것으로 보 고되었고 [12-15], 정신건강 관련성에 대한 메타분석 결과 에서는 식품불안정은 우울 증상 위험도를 2.74 배, 불안장애 위험도를 2.41 배, 수면장애 위험도를 1.80 배 유의하게 증 가시켰다 [16]. 우리나라 노인 대상의 연구에서도 식품불안 정은 스트레스, 우울증, 자살생각과 같은 정신건강과 관련이 있었다[17]. 또한 사회 구성원 사이의 협조를 가능하게 하 는 연결망 (network)을 의미하는 사회자본 (social capital) 과 근린환경도 식품불안정과 관련이 있는 것으로 보고되었 다 $[18,19]$.

이와 같이 식품불안정은 개인, 가구, 지역사회 등 여러 수 준에서 경제적, 사회적, 환경적 요인을 반영한 복합적인 현 상으로, 식품불안정과 관련된 요인을 파악하고 해결 전략을 세우는데 사회생태학적 모델이 유용하게 활용되고 있다 [20, 21]. 보건분야에 적용되는 사회생태학적 모델의 중요한 개 념은 개인의 행동에 대한 다양한 영향 중에서 환경을 여러 수 준으로 설명하는 것으로 [22], 예를 들면 식행동에 영향을 주 는 요인을 (1) 사회인구학적 특성, 지식, 태도 등의 개인적
요인 (intrapersonal factors), (2) 가족, 친구 등의 사회적 연결망, 사회적 지지 등의 개인간 요인 (interpersonal factors, social environmental factors), (3) 식품의 접 근성에 영향을 줄 수 있는 학교, 직장, 주위 상점 등의 지역 사회 요인(community factors, physical environmental factors), (4) 대중매체, 사회문화적 규범, 식품분 배 시스템, 정책, 법 등의 거시적 시스템 (macrosystem factors)의 여러 수준으로 설명한다 [23]. 따라서 이러한 모 델을 근거로 식품불안정에 영향을 주는 개인적 요인 뿐 아니 라 사회적, 환경적 요인 등을 체계적으로 탐색함으로써 건강 격차 해소를 위한 노력이 필요할 것이다.

국내의 식품안정성 관련 연구는 2005년부터 국민건강영 양조사에서 식품안정성을 조사하기 위한 단일문항을 추가하 면서, 식품 섭취와의 관련성 $[7,11,17,24-26]$, 건강상태 와의 관련성 $[9,17,25,26]$ 에 대한 연구가 진행되어 왔다. 최근에는 지역사회건강조사 자료를 활용하여 식품불안정에 영향을 미칠 수 있는 지역사회의 특성을 분석하여, 지역의 재 정자립도나 복지예산이 낮고, 실업률이 높은 환경일수록 식 품불안정 수준이 높다는 결과를 제시한 바 있으나 [8], 개인 적 요인, 개인간 요인 및 지역사회 요인에 대하여 종합적으 로 분석하여 보고된 바는 없다.

또한 식품안정성에 대한 대부분의 선행연구는 충분한 식 품이 공급되는 양적 제공을 기준으로 안정과 불안정을 구분 하고 있지만, 식품안정성은 단순히 식품의 양적인 충족을 의 미하는 것이 아니라 충분한 영양을 공급할 수 있도록 질적으 로 우수한 다양한 식품의 확보를 포함하고 있다[1]. 식품불 안정 가구의 식사 질 관련 연구 결과 식품불안정 가구원은 식 품의 다양성이 낮았고, 특히 채소류와 과일류의 다양성이 부 족하였다 $[7,10,24]$. 식품의 다양성은 여러 가지 영양소의 섭취량과 비례하며 [27], 위암, 대장암, 구강암 등의 위험을 낮추고 [28-30], 사망률과 역의 관련성이 있음이 보고되었 다 [31]. 이와 같이 식품을 다양하게 섭취하는 것은 건강한 삶을 위한 가장 기본적인 식생활 지침으로, 2016년 국민공 통식생활지침에는 ‘쌀 - 잡곡, 채소, 과일, 우유 - 유제품, 육 류, 생선, 달걀, 콩류 등 다양한 식품을 섭취하자'가 강조되 었고 [32], 제4차 국민건강증진종합계획 (Health Plan) 영 양부문에서도 ‘과일류와 채소류를 1 일 $500 \mathrm{~g}$ 이상 섭취하 는 만 6 세 이상의 인구비율에 대하여 소득 4 분위수의 최하 위와 최상위 간 차이를 $11.2 \% \mathrm{p}$ 미만’을 목표로 관리하는 중 요한 사항이다 [4].

비만 등 만성질환이 증가하고 있는 현대 식생활에서는 식 품의 양적 부족보다 다양성을 보장받지 못한 식품불안정에 따른 건강 격차의 우려가 지속적으로 대두되고 있으나, 다양 
성에 초점을 맞춘 식품안정성에 대한 연구는 부족한 실정이 다. 따라서 본 연구에서는 2017년 지역사회건강조사 자료 를 활용하여 식품충분성과 다양성을 고려하여 집단을 분류 하고, 집단별 사회인구학적 특성 뿐 아니라 개인간 요인 및 지역사회 요인들의 차이를 파악하여 식품충분성 및 다양성 과 관련된 요인을 규명하고자 하였다.

\section{연구대상 및 방법}

\section{1. 연구 대상 및 조사 기간}

본 연구는 질병관리본부의 2017년 지역사회건강조사 (Community Health Survey) 원시자료를 이용하였다. 지 역사회건강조사는 지역보건법에 근거하여 지역보건의료계 획 수립 및 평가를 위한 지역건강 통계를 생산하는 것을 목 적으로 2008년부터 매년 전국 보건소에서 시행되고 있는 조 사로 건강행태, 이환, 의료이용, 사회물리적 환경 등 개인 및 지역 단위에서의 건강 관련 문항들이 포함되어 있다 [33]. 목 표 모집단은 2017년 7월 기준으로 전국 시 · 군 · 구에 거주 하는 만 19 세 이상의 성인이고, 조사 대상은 조사시점에 선 정된 표본가구에 거주하는 만 19 세 이상 성인이다. 표본추 출은 1 차로 통 · 반/리 내 주택유형별 가구 수를 기준으로 표 본지점을 추출한 뒤, 2 차 계통추출법으로 최종 표본가구를 선정하는 복합 표본 설계로 구성되었다. 조사는 2017년 8 월 16일부터 10월 31 일 사이 훈련된 조사원이 표본가구를 방문하여 노트북에 탑재된 총 201항목의 전자설문조사표를 이용하여 조사대상자와 1:1 면접방식 (Computer Assisted Personal Interviewing)으로 이루어졌다. 2017년 조사에 참여한 대상자 228,381 명 중 식품안정성을 묻는 단일문항 의 응답자료가 불충분한 71 명의 자료를 제외한 228,310 명 의 자료를 최종 분석에 이용하였다. 본 연구는 충북대학교 생 명윤리심의위원회에서 심의 면제 (CBNU-202006-0084) 를 받았다.

\section{2. 연구내용 및 방법}

\section{1) 식품충분성 및 다양성에 따른 집단 분류}

식품안정성에 대한 단일문항인 '다음 중 최근 1 년 동안 귀 댁의 식생활 형편을 가장 잘 나타낸 것은 어느 것입니까?'에 대한 4 개의 응답항목 중 ‘우리 식구 모두가 원하는 만큼의 충 분한 양과 다양한 종류의 음식을 먹을 수 있었다'에 응답한 경우 다양성이 확보된 식품충분군 (식품충분 - 다양군)으로, ‘우리 식구 모두가 충분한 양의 음식을 먹을 수 있었으나, 다 양한 종류의 음식은 먹지 못했다'에 응답한 경우 다양성이 확 보되지 못한 식품충분군 (식품충분 · 비다양군)으로, '경제적
으로 어려워서 가끔 먹을 것이 부족했다'와 '경제적으로 어 려워서 자주 먹을 것이 부족했다'에 응답한 경우 식품불충분 군으로 대상자를 분류하였다.

\section{2) 개인적 요인}

개인적 요인은 대상자의 인구사회학적 특성, 건강행동 및 건강상태 문항 자료를 이용하였다. 인구사회학적 특성은 성 별, 연령, 교육수준, 가구소득, 직업여부, 결혼여부, 거주지역 의 인구규모를 포함하였다. 대상자가 거주하는 지역은 소방 력, 지방자치법 및 도시군기본계획의 도시기준에 근거하여 인구규모에 따라 4 개 집단으로 분류한 선행연구 방법으로 분 류하였다 [35]. 본 연구의 표본지점 인구수를 국가통계포털 의 2017년 지역별 인구수와 비교하여, 인구 50만 이상은 '대규모 지역 (large population)', 30만 50만은 ‘중규모 지역 (medium population)', 10만 30만은 ‘소규모 지역 (small population)', 10만 미만은 ‘극소규모 지역 (very small poulation)'으로 분류하였다.

건강행동은 조사일을 기준으로 금연, 금주, 중등도 신체활 동, 적절한 수면, 규칙적 아침식사에 대한 항목의 실천 여부 를 포함하였다. 과거 흡연과 과거 음주는 각각 금연과 금주 행동 실천으로 분류하였고, 최근 1 주일 동안 중등도 이상의 신체활동을 5 일 이상 한 경우를 중등도 신체활동 실천으로 분류하였다. 하루 7 8시간의 수면과 최근 1 주일 동안 5 일 이상의 아침식사를 하는 경우를 각각 적절한 수면과 규칙적 아침식사 실천으로 분류하였다.

건강상태 중 과체중/비만은 응답자가 보고한 신장과 체중 을 이용하여 체질량지수 (Body Mass Index, BMI)를 산출 하고 세계보건기구 아시아-태평양 지역의 비만기준에 따라 BMI $23.0 \mathrm{~kg} / \mathrm{m}^{2}$ 이상을 과체중/비만으로 판정하여 분류하 였으며 [34], 그 외 당뇨, 고혈압, 이상지질혈증 및 관절염은 의사 진단여부에 따라 '있음'과 '없음'으로 분류하였다.

\section{3) 개인간 요인}

개인간 요인은 사회적 연결망과 사회적 활동에 대한 설문 문항을 활용하였다. 사회적 연결망은 응답자가 친척, 이웃, 친구와 만남이나 연락하는 빈도를 조사한 항목으로 주 1 회 이상인 경우를 ‘예', 주 1 회 미만의 경우를 ‘아니오'로 분류 하였다. 사회적 활동은 응답자가 친목활동, 여가/레저 활동, 종교활동 및 자선단체 활동에 대해 월 1 회 이상 정기적으로 참여하는지에 대한 응답으로 ‘예' 또는 ‘아니오'를 사용하였다.

\section{4) 지역사회 요인}

지역사회의 환경에 관한 문항으로는 전반적 안전수준 (자 
연재해, 교통사고, 농작업 사고, 범죄 등), 자연환경 (공기질, 수질 등), 생활환경 (전기, 상하수도, 스포츠시설 등), 대중교 통 (버스, 택시 등) 및 의료서비스 (보건소, 병의원, 약국 등) 에 대한 만족 여부에 따라 ‘예' 또는 '아니오'의 응답을 사용 하였다.

\section{3. 통계 분석}

본 연구의 자료는 SAS 9.4 (SAS Institute Inc., Cary, $\mathrm{NC}, \mathrm{USA}$ ) 프로그램을 사용하여 분석하였다. 2017년 지역 사회건강조사 원시자료 이용지침에 따라 복합표본 설계의 효 과를 고려하여 층화변수, 집락변수 및 개인 가중치를 적용하 였다. 개인적 요인 (인구사회학적 특성, 건강행동 및 건강상 태), 개인간 요인 (사회적 연결망 및 사회적 활동) 및 지역사 회 요인에 대하여 식품충분성 및 다양성에 따른 집단별 빈도 와 백분율 (\%)을, 연령은 평균과 표준편차를 구하고 복합표 본 설계를 고려한 분석을 위해 SAS의 survey procedure 를 이용하였다.

식품충분성 및 다양성에 대한 관련 요인 분석은 종속변수 가 3 개의 범주형 명목변수 (식품충분 · 다양군, 식품충분 비다양군, 식품불충분군)인 점을 고려하여 다항로지스틱 회 귀분석(multinomial logistic regression analysis)을 실시하였다. 이를 통해 식품충분 - 다양군과 비교한 식품충 분 - 비다양군과 식품불충분군의 교차비 (odds ratos) 와 95\% 신뢰구간을 구하였다. 이 때 성별, 연령집단, 교육수준, 가구소득, 직업여부, 결혼여부, 거주지역의 인구규모의 사회 인구학적 요인을 교란변수로 보정하여 개인간 요인과 지역 사회 요인에 대한 다변량분석을 실시하였고 (Model I), 사회 인구학적 요인, 개인간 요인, 지역사회 요인을 함께 고려하 여 모두 모델에 넣은 다변량분석을 실시하였다 (Model II). 또한 식품충분 · 비다양군과 비교한 식품불충분군의 교차비 와 $95 \%$ 신뢰구간을 구하기 위해 이항로지스틱 회귀분석을 실시하였고, 이 때에도 사회인구학적 요인을 교란변수로 보 정하여 개인간 요인과 지역사회 요인에 대한 다변량분석 (Model III) 및 사회인구학적 요인, 개인간 요인, 지역사회 요인을 모두 모델에 넣은 다변량분석을 실시하였다 (Model IV). 모든 통계분석의 유의성은 $P<0.05$ 수준에서 검증하 였다.

\section{결 과}

\section{1. 식품충분성 및 다양성에 따른 개인적 요인}

연구 대상자 228,310명 중 식품충분 · 다양군은 $65.3 \%$, 식품충분 · 비다양군은 $31.5 \%$, 식품불충분군은 $3.2 \%$ 이었
다. 세 집단의 인구사회학적 특성은 Table 1 과 같이, 성별, 연령, 교육수준, 가구소득, 직업, 결혼상태, 거주지역의 인구 규모 등 모든 변수에서 유의적인 차이가 있었으며 $(P<$ $0.0001)$, 식품충분 · 비다양군을 식품충분 · 다양군, 식품불 충분군과 각각 비교하였을 때에도 모든 변수에 유의적인 차 이가 있었다 $(P<0.0001)$. 여성과 65세 이상 인구 비율은 식품불충분군에서 가장 높았고, 식품충분 - 비다양군, 식품 충분 · 다양군의 순이었으며, 조사대상자의 평균 연령도 식 품충분 · 다양군은 45.9세, 식품충분 · 비다양군은 49.9세 및 식품불충분군은 59.3세로 집단에 따라 유의적인 차이가 있었다 $(P<0.0001)$. 식품충분 - 다양군은 대학 이상 (47.8\%), 식품충분 - 비다양군은 고등학교 졸업 (38.5\%), 식품불충분군은 초등학교 졸업 이하 $(44.2 \%)$ 의 비율이 각 각 가장 높았다. 가구소득이 월 평균 100 만원 미만은 식품 충분 - 다양군이 $4.5 \%$ 인데 비해, 식품충분 - 비다양군은 $18.5 \%$, 식품불충분군이 $64.3 \%$ 로 큰 차이가 있었다. 식품 충분 - 다양군은 직업이 있는 경우와 배우자가 있는 경우에 서도 가장 높은 비율을 나타냈다. 거주지역 규모의 경우 식 품충분 - 다양군에서는 식품충분 · 비다양군 및 식품불충분 군에 비해 대규모와 중규모 지역에 거주하는 비율이 높았고, 소규모와 극소규모에 거주하는 비율은 낮았다 $(P<0.0001)$.

거주지역의 인구 규모에 따른 식품충분 · 다양군, 식품충 분 · 비다양군 및 식품불충분군의 분포를 Fig. 1 에 제시하였 다. 식품충분 - 다양군은 대규모 지역에서는 $69.2 \%$ 로 가장 높았고, 소규모 지역에서는 $57.2 \%$ 로 가장 낮았다. 식품충 분 - 비다양군의 분포는 대규모 $28.3 \%$, 중규모 $30.5 \%$, 소 규모 $34.2 \%$, 극소규모 $38.5 \%$ 순으로, 식품불충분군과 마 찬가지로 인구 규모가 작은 지역일수록 빈도가 높았다.

식품충분성 및 다양성에 따른 대상자의 건강행동 및 건강 상태는 Table 2 와 같다. 모든 건강행동과 건강상태에서 세 집단의 분포에는 유의적인 차이가 있었다. 금연 실천 비율은 식품충분 - 다양군이 $80.5 \%$ 로 가장 높은 반면, 금주 실천 비 율은 식품충분 - 다양군이 $21.6 \%$ 로 가장 낮았고, 식품충 분 - 비다양군과 식품불충분군은 각각 $28.2 \%, 47.0 \%$ 였다 (모두 $P<0.0001$ ). 중등도 이상의 신체활동 실천과 $7 \sim 8$ 시간 적절한 수면시간 실천의 경우 식품충분 - 다양군, 식품 충분 · 비다양군, 식품불충분군 순으로 식품충분 - 다양군의 실천 비율이 가장 높았으나, 규칙적인 아침식사 실천의 경우 식품불충분군에서 가장 높았다 (모두 $P<0.0001$ ). 식품충 분 · 비다양군은 아침식사 실천에서만 식품충분 · 다양군과 유의적인 차이가 없었고, 그 외 다른 건강행동 실천에서는 식 품충분 - 다양군, 식품불충분군과 각각 유의적인 차이가 있 었다. 
420 - 식품충분성과 다양성의 개인간 및 지역수준 관련 요인

Table 1. Sociodemographic characteristics according to food sufficiency and variety

\begin{tabular}{|c|c|c|c|c|c|c|c|}
\hline Variables & $\begin{array}{c}\text { Total } \\
(\mathrm{n}=228,310)\end{array}$ & $\begin{array}{c}\text { Food sufficiency } \\
\text { with variety } \\
(n=137,093)\end{array}$ & $\begin{array}{l}\text { Food sufficiency } \\
\text { without variety } \\
(n=81,857)\end{array}$ & $\begin{array}{c}\text { Food } \\
\text { insufficiency } \\
(n=9,360)\end{array}$ & P-value & $P$-value ${ }^{2)}$ & $P$-value ${ }^{3)}$ \\
\hline \multicolumn{8}{|l|}{ Sex } \\
\hline Male & 49.6 & 49.9 & 49.3 & 45.3 & \multirow[t]{2}{*}{$<0.0001$} & \multirow[t]{2}{*}{0.0087} & \multirow[t]{2}{*}{$<0.0001$} \\
\hline Female & 50.4 & 50.1 & 50.7 & 54.7 & & & \\
\hline \multicolumn{8}{|l|}{ Age group (years) } \\
\hline $19 \sim 44$ & 44.6 & 48.0 & 39.7 & 21.3 & \multirow[t]{4}{*}{$<0.0001$} & \multirow[t]{4}{*}{$<0.0001$} & \multirow[t]{4}{*}{$<0.0001$} \\
\hline $45 \sim 64$ & 37.9 & 38.8 & 36.7 & 32.7 & & & \\
\hline $65 \sim 74$ & 10.2 & 8.5 & 12.7 & 21.5 & & & \\
\hline$\geq 75$ & 7.3 & 4.7 & 10.9 & 24.5 & & & \\
\hline Average age (years) & $47.6 \pm 0.05$ & $45.9 \pm 0.06$ & $49.9 \pm 0.09$ & $59.3 \pm 0.24$ & & & \\
\hline \multicolumn{8}{|l|}{ Education level } \\
\hline$\leq$ Elementary school & 13.0 & 8.2 & 19.8 & 44.2 & \multirow[t]{4}{*}{$<0.0001$} & \multirow[t]{4}{*}{$<0.0001$} & \multirow[t]{4}{*}{$<0.0001$} \\
\hline Middle school & 8.3 & 7.0 & 10.4 & 14.8 & & & \\
\hline High school & 37.3 & 37.0 & 38.5 & 29.7 & & & \\
\hline$\geq$ College & 41.4 & 47.8 & 31.3 & 11.2 & & & \\
\hline \multicolumn{8}{|c|}{ Household income (10,000 won/month) } \\
\hline$<100$ & 10.8 & 4.5 & 18.5 & 64.3 & \multirow[t]{5}{*}{$<0.0001$} & \multirow[t]{5}{*}{$<0.0001$} & \multirow[t]{5}{*}{$<0.0001$} \\
\hline $100 \sim 200$ & 12.2 & 8.6 & 18.5 & 21.2 & & & \\
\hline $200 \sim 300$ & 17.1 & 15.5 & 21.2 & 8.4 & & & \\
\hline $300 \sim 400$ & 17.9 & 19.0 & 17.2 & 3.9 & & & \\
\hline$\geq 400$ & 42.0 & 52.4 & 24.5 & 2.2 & & & \\
\hline \multicolumn{8}{|l|}{ Employment } \\
\hline Employed & 64.4 & 67.4 & 61.3 & 35.0 & \multirow[t]{2}{*}{$<0.0001$} & \multirow[t]{2}{*}{$<0.0001$} & \multirow[t]{2}{*}{$<0.0001$} \\
\hline Unemployed & 35.6 & 32.6 & 38.7 & 65.0 & & & \\
\hline \multicolumn{8}{|l|}{ Marital status } \\
\hline With spouse & 65.0 & 69.5 & 58.2 & 39.6 & \multirow[t]{2}{*}{$<0.0001$} & \multirow[t]{2}{*}{$<0.0001$} & \multirow[t]{2}{*}{$<0.0001$} \\
\hline Without spouse/single & 35.0 & 30.5 & 41.8 & 60.4 & & & \\
\hline \multicolumn{8}{|c|}{ Population size of residence (10,000 person) } \\
\hline Very small $(\leq 10)$ & 9.3 & 8.2 & 11.4 & 12.8 & \multirow[t]{4}{*}{$<0.0001$} & \multirow[t]{4}{*}{$<0.0001$} & \multirow[t]{4}{*}{0.0002} \\
\hline Small (10 30) & 26.5 & 25.3 & 28.8 & 30.2 & & & \\
\hline Medium (30 50) & 32.9 & 33.5 & 31.8 & 32.5 & & & \\
\hline Large ( $\geq 50)$ & 31.2 & 33.1 & 28.1 & 24.5 & & & \\
\hline
\end{tabular}

$\%$ or Mean \pm SE. All the estimates were produced to represent the Korean population using sample weight.

Taylor series method was applied to the variance estimation to account for multistage sampling and unequally weighted.

1) By Rao-Scott $\chi^{2}$-test among the three groups

2) By Rao-Scott $\chi^{2}$-test between the food-sufficiency-with-variety group and the food-sufficiency-without-variety group

3) By Rao-Scott $\chi^{2}$-test between the ffood-sufficiency-without-variety group and the food-insufficiency group

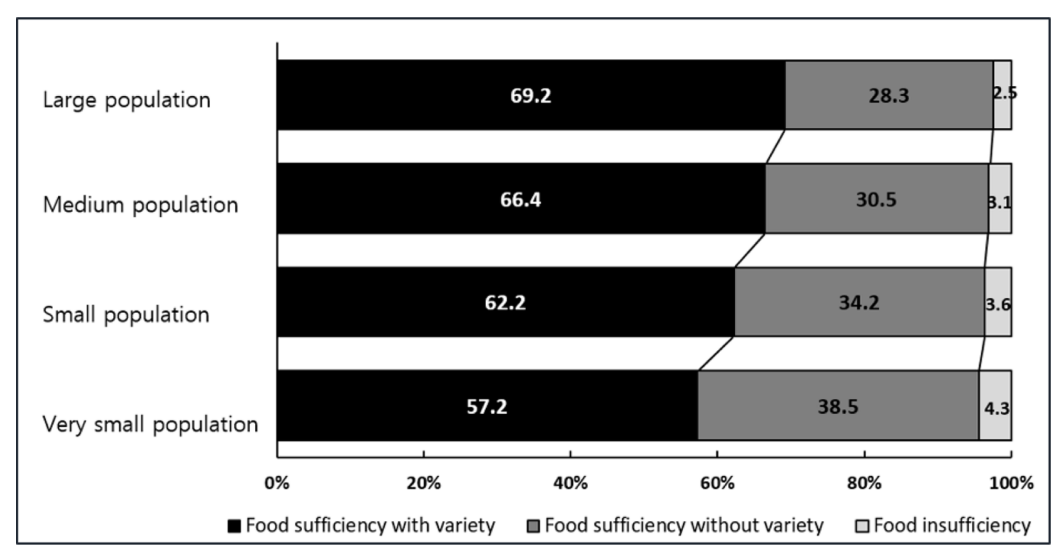

Fig. 1. Distribution of the three groups based on food sufficiency and variety by population size of residence 
Table 2. Health behaviors and health status according to food sufficiency and variety

\begin{tabular}{|c|c|c|c|c|c|c|c|}
\hline Variables & $\begin{array}{c}\text { Total } \\
(n=228,310)\end{array}$ & $\begin{array}{l}\text { Food sufficiency } \\
\text { with variety } \\
(n=137,093)\end{array}$ & $\begin{array}{l}\text { Food sufficiency } \\
\text { without variety } \\
(n=81,857)\end{array}$ & $\begin{array}{c}\text { Food } \\
\text { insufficiency } \\
(n=9,360)\end{array}$ & P-value ${ }^{11}$ & $P$-value ${ }^{21}$ & $P$-value ${ }^{3 l}$ \\
\hline \multicolumn{8}{|l|}{ Health behaviors } \\
\hline \multicolumn{8}{|l|}{ Non-smoking } \\
\hline Yes & 79.8 & 80.5 & 78.8 & 76.7 & $<0.0001$ & $<0.0001$ & 0.0018 \\
\hline No & 20.2 & 19.5 & 21.2 & 23.3 & & & \\
\hline \multicolumn{8}{|l|}{ Non-drinking } \\
\hline Yes & 24.5 & 21.6 & 28.2 & 47.0 & $<0.0001$ & $<0.0001$ & $<0.0001$ \\
\hline No & 75.5 & 78.4 & 71.8 & 53.0 & & & \\
\hline \multicolumn{8}{|c|}{ Moderate physical activity ( $\geq 5 /$ week) } \\
\hline Yes & 22.2 & 23.6 & 20.0 & 15.2 & $<0.0001$ & $<0.0001$ & $<0.0001$ \\
\hline No & 77.8 & 76.4 & 80.0 & 84.8 & & & \\
\hline \multicolumn{8}{|c|}{ Adequate sleep (7 8 hours) } \\
\hline Yes & 48.4 & 49.3 & 47.4 & 40.6 & $<0.0001$ & $<0.0001$ & $<0.0001$ \\
\hline No & 51.6 & 50.7 & 52.6 & 59.4 & & & \\
\hline \multicolumn{8}{|c|}{ Regular breakfast ( $\geq 5 /$ week) } \\
\hline Yes & 67.5 & 67.1 & 67.7 & 73.4 & $<0.0001$ & 0.0648 & $<0.0001$ \\
\hline No & 32.5 & 32.9 & 32.3 & 26.6 & & & \\
\hline \multicolumn{8}{|l|}{ Health status } \\
\hline \multicolumn{8}{|c|}{ Overweight/Obesity } \\
\hline Yes & 51.5 & 51.9 & 50.9 & 49.0 & 0.0021 & 0.0005 & 0.0141 \\
\hline No & 48.5 & 48.1 & 49.1 & 51.0 & & & \\
\hline \multicolumn{8}{|l|}{ Hypertension } \\
\hline Yes & 20.3 & 17.8 & 23.7 & 38.1 & $<0.0001$ & $<0.0001$ & $<0.0001$ \\
\hline No & 79.7 & 82.2 & 76.3 & 61.9 & & & \\
\hline \multicolumn{8}{|l|}{ Diabetes } \\
\hline Yes & 8.3 & 7.1 & 9.8 & 18.6 & $<0.0001$ & $<0.0001$ & $<0.0001$ \\
\hline No & 91.7 & 92.9 & 90.2 & 81.4 & & & \\
\hline \multicolumn{8}{|l|}{ Dyslipidemia } \\
\hline Yes & 15.1 & 14.2 & 16.4 & 22.4 & $<0.0001$ & $<0.0001$ & $<0.0001$ \\
\hline No & 84.9 & 85.8 & 83.6 & 77.6 & & & \\
\hline \multicolumn{8}{|l|}{ Arthritis } \\
\hline Yes & 10.2 & 7.9 & 13.3 & 26.4 & $<0.0001$ & $<0.0001$ & $<0.0001$ \\
\hline No & 89.8 & 92.1 & 86.7 & 73.6 & & & \\
\hline
\end{tabular}

$\%$. All the estimates were produced to represent the Korean population using sample weight.

Taylor series method was applied to the variance estimation to account for multistage sampling and unequally weighted.

1) By Rao-Scott $\chi^{2}$-test among the three groups

2) By Rao-Scott $\chi^{2}$-test between the food-sufficiency-with-variety group and the food-sufficiency-without-variety group

3) By Rao-Scott $\chi^{2}$-test between the food-sufficiency-without-variety group and the food-insufficiency group

조사 대상자의 건강상태 중 과체중 이상의 비율이 $51.5 \%$ 로 가장 높았고, 고혈압 $20.3 \%$, 이상지질혈증 $15.1 \%$, 관절 염 $10.2 \%$, 당뇨병 $8.3 \%$ 순이었다. 식품충분 · 다양군의 과 체중 이상 비율 $(51.9 \%)$ 은 식품충분 · 비다양군 $(50.9 \%)$ 과 식품불충분군 $(49.0 \%)$ 에 비해 높았고 $(P=0.0021)$, 비만 을 제외한 고혈압, 당뇨, 이상지질혈증 및 관절염 진단 비율
은 식품불충분군에서 가장 높았으며, 식품충분 - 비다양군, 식품충분 - 다양군의 순이었다 (모두 $P<0.0001$ ). 특히, 관 절염의 경우 식품충분 - 비다양군 $(13.3 \%)$ 과 식품불충분군 (26.4\%)은 식품충분 - 다양군 $(7.9 \%)$ 에 비해 각각 1.7 배, 3.3 배 많았다. 식품충분 - 비다양군은 모든 건강상태에서 식 품충분 - 다양군, 식품불충분군과 각각 유의적인 차이가 있었다. 


\section{2. 식품충분성 및 다양성에 따른 개인간 요인}

식품충분성 및 다양성에 따른 대상자의 개인간 요인의 분 포는 Table 3에 제시하였으며, 모든 요인에서 집단별 분포 에 유의적인 차이가 있었고 (모두 $P<0.0001$ ), 식품충분 · 비다양군은 식품충분 · 다양군, 식품불충분군과 각각 차이가 있었다 (모두 $P<0.0001$ ). 사회적 연결망의 경우, 친척과 친구와의 주 1 회 이상 관계를 유지하고 있는 비율은 식품충 분 - 다양군이 가장 높았고 식품불충분군이 가장 낮았다. 반 면 이웃과의 관계에서는 식품충분 - 다양군 $(37.6 \%)$ 이 가장 낮았고 식품불충분군 $(44.8 \%)$ 이 가장 높았다. 조사 대상자 전체의 사회적 활동은 친목 활동 $(52.7 \%)$, 여가/레저 활동 (32.6\%), 종교 활동 $(26.0 \%)$, 자선단체 활동 $(7.7 \%)$ 순이 었으며, 이 중 친목, 여가/레저 및 자선단체 활동은 모두 식 품충분 - 다양군이 가장 높았고, 식품충분 - 비다양군, 식품 불충분군의 순이었다. 그러나 종교 활동은 식품불충분군이
$28.7 \%$ 로 가장 높았고, 식품충분 · 비다양군이 $25.0 \%$ 로 가 장 낮았다.

\section{3. 식품충분성 및 다양성에 따른 지역사회 요인}

식품충분성 및 다양성에 따른 대상자의 지역사회 요인의 분포는 Table 4 와 같다. 안전수준, 자연환경 및 생활환경에 대해 만족한다는 응답 비율은 식품충분 - 다양군이 가장 높 았고 식품충분 - 비다양군, 식품불충분군 순으로 비율이 낮 아졌으며 (모두 $P<0.0001$ ), 식품충분 · 비다양군은 식품 충분 - 다양군, 식품불충분군과도 각각 차이가 있었다. 반면, 대중교통과 의료서비스에 만족하는 응답은 식품충분 - 다양 군이 가장 높은 비율인 것과 세 집단에 유의적 차이가 있었 던 것은 동일하였으나 (각각 $P=0.0005, P<0.0001$ ), 두 집단씩 비교하였을 때 식품충분 - 비다양군이 식품불충분군 과는 차이가 없었다.

Table 3. Interpersonal factors according to food sufficiency and variety

\begin{tabular}{|c|c|c|c|c|c|c|c|}
\hline Variables & $\begin{array}{c}\text { Total } \\
(\mathrm{n}=228,310)\end{array}$ & $\begin{array}{c}\text { Food sufficiency } \\
\text { with variety } \\
(n=137,093)\end{array}$ & $\begin{array}{c}\text { Food sufficiency } \\
\text { without variety } \\
(n=81,857)\end{array}$ & $\begin{array}{c}\text { Food } \\
\text { insufficiency } \\
(n=9,360) \\
\end{array}$ & $P$-value ${ }^{11}$ & $P$-value ${ }^{2)}$ & $P$-value ${ }^{3 j}$ \\
\hline \multicolumn{8}{|c|}{ Social network ( $\geq 1 /$ week) } \\
\hline \multicolumn{8}{|l|}{ Relatives } \\
\hline Yes & 52.0 & 54.0 & 49.1 & 40.1 & $<0.0001$ & $<0.0001$ & $<0.0001$ \\
\hline No & 48.0 & 46.0 & 50.9 & 59.9 & & & \\
\hline \multicolumn{8}{|l|}{ Neighbors } \\
\hline Yes & 38.4 & 37.6 & 39.3 & 44.8 & $<0.0001$ & $<0.0001$ & $<0.0001$ \\
\hline No & 61.6 & 62.4 & 60.7 & 55.2 & & & \\
\hline \multicolumn{8}{|l|}{ Friends } \\
\hline Yes & 54.1 & 56.0 & 51.3 & 42.1 & $<0.0001$ & $<0.0001$ & $<0.0001$ \\
\hline No & 45.9 & 44.0 & 48.7 & 57.9 & & & \\
\hline \multicolumn{8}{|c|}{ Social activities ( $\geq 1 /$ month) } \\
\hline \multicolumn{8}{|c|}{ Social gathering } \\
\hline Yes & 52.7 & 56.2 & 47.8 & 30.4 & $<0.0001$ & $<0.0001$ & $<0.0001$ \\
\hline No & 47.3 & 43.8 & 52.3 & 69.6 & & & \\
\hline \multicolumn{8}{|c|}{ Leisure activity } \\
\hline Yes & 32.6 & 37.3 & 25.1 & 11.7 & $<0.0001$ & $<0.0001$ & $<0.0001$ \\
\hline No & 67.4 & 62.7 & 74.9 & 88.3 & & & \\
\hline \multicolumn{8}{|c|}{ Religious activity } \\
\hline Yes & 26.0 & 26.3 & 25.0 & 28.7 & $<0.0001$ & $<0.0001$ & $<0.0001$ \\
\hline No & 74.0 & 73.7 & 75.0 & 71.3 & & & \\
\hline \multicolumn{8}{|c|}{ Charity activity } \\
\hline Yes & 7.7 & 9.0 & 5.6 & 3.5 & $<0.0001$ & $<0.0001$ & $<0.0001$ \\
\hline No & 92.3 & 91.0 & 94.4 & 96.5 & & & \\
\hline
\end{tabular}

$\%$. All the estimates were produced to represent the Korean population using sample weight.

Taylor series method was applied to the variance estimation to account for multistage sampling and unequally weighted.

1) By Rao-Scott $\chi^{2}$-test among the three groups

2) By Rao-Scott $\chi^{2}$-test between the food-sufficiency-with-variety group and the food-sufficiency-without-variety group

3) By Rao-Scott $\chi^{2}$-test between the food-sufficiency-without-variety group and the food-insufficiency group 
Table 4. Community factors according to food sufficiency and variety

\begin{tabular}{|c|c|c|c|c|c|c|c|}
\hline Variables & $\begin{array}{c}\text { Total } \\
(\mathrm{n}=228,310)\end{array}$ & $\begin{array}{c}\text { Food sufficiency with } \\
\text { variety } \\
(n=137,093)\end{array}$ & $\begin{array}{l}\text { Food sufficiency } \\
\text { without variety } \\
(n=81,857)\end{array}$ & $\begin{array}{c}\text { Food } \\
\text { insufficiency } \\
(n=9,360)\end{array}$ & $P$-value ${ }^{\prime \prime}$ & $P$-value ${ }^{2 l}$ & $P$-value ${ }^{3 l}$ \\
\hline \multicolumn{8}{|l|}{ Safety } \\
\hline Satisfied & 77.9 & 79.2 & 75.9 & 69.7 & $<0.0001$ & $<0.0001$ & $<0.0001$ \\
\hline Unsatisfied & 22.1 & 20.8 & 24.1 & 30.3 & & & \\
\hline \multicolumn{8}{|l|}{ Natural environment } \\
\hline Satisfied & 75.6 & 75.9 & 74.9 & 73.4 & $<0.0001$ & 0.0012 & 0.0464 \\
\hline Unsatisfied & 24.4 & 24.1 & 25.1 & 26.6 & & & \\
\hline \multicolumn{8}{|l|}{ Living environment } \\
\hline Satisfied & 81.6 & 82.9 & 79.3 & 76.9 & $<0.0001$ & $<0.0001$ & 0.0002 \\
\hline Unsatisfied & 18.4 & 17.1 & 20.7 & 23.1 & & & \\
\hline \multicolumn{8}{|l|}{ Public transportation } \\
\hline Satisfied & 75.0 & 75.4 & 74.3 & 74.5 & 0.0005 & 0.0004 & 0.8526 \\
\hline Unsatisfied & 25.0 & 24.6 & 25.7 & 25.5 & & & \\
\hline \multicolumn{8}{|l|}{ Health care services } \\
\hline Satisfied & 75.4 & 76.5 & 73.4 & 73.6 & $<0.0001$ & $<0.0001$ & 0.7624 \\
\hline Unsatisfied & 24.6 & 23.5 & 26.6 & 26.4 & & & \\
\hline
\end{tabular}

$\%$. All the estimates were produced to represent the Korean population using sample weight.

Taylor series method was applied to the variance estimation to account for multistage sampling and unequally weighted.

1) By Rao-Scott $\chi^{2}$-test among the three groups

2) By Rao-Scott $\chi^{2}$-test between the food-sufficiency-with-variety group and the food-sufficiency-without variety group

3) By Rao-Scott $\chi^{2}$-test between the food-sufficiency-without-variety group and the food-insufficiency group

\section{4. 식품충분성 및 다양성과 관련된 개인간 및 지역사회 요인}

식품충분성 및 다양성과 관련된 개인간 요인과 지역사회 요인을 파악하기 위해 여러 가지 요인으로 보정한 후 로지스 틱 회귀분석으로 식품충분 - 다양군과의 교차비 (Model I, II) 와 식품충분 · 비다양군과의 교차비 (Model III, IV)로 나 누어 Table 5에 제시하였다. 개인간 요인과 지역사회 요인 을 사회인구학적 특성으로 보정한 모델에서 (Model I), 다양 성이 확보된 식품충분성을 기준으로 하였을 경우에는 친척, 이웃, 친구와의 연결망이 주 1 회 미만이거나 사회적 활동이 월 1 회 미만인 대상자들의 다양성이 확보되지 않은 식품충 분성과 식품불충분성의 위험이 교차비 1 이상으로 증가하였 고, 식품불충분군의 종교활동을 제외하고는 모두 통계적으 로 유의하였다. 또한 다양성이 확보된 식품충분성을 기준으 로 지역사회 요인을 평가하였을 때에도 안전수준, 자연환경, 생활환경, 대중교통, 의료서비스 등에 불만족인 대상자의 다 양성이 확보되지 않은 식품충분성과 식품불충분성의 위험이 유의적으로 증가하였다. 식품충분 · 비다양군에서는 생활환 경 불만족인 교차비가 $1.27(95 \% \mathrm{CI}: 1.23 \sim 1.32, P<$ $0.0001)$ 로 가장 높았고, 식품불충분군에서는 안전수준 불 만족인 교차비가 $1.92(95 \%$ CI : 1.77 2.09, $P<0.0001)$ 로 가장 높았다. 즉, 식품충분 · 비다양군과 식품불충분군은 식품충분 - 다양군에 비해 사회적 연결망과 사회적 활동이
덜 활발하였고, 지역사회 환경에 대해 덜 만족한다는 것을 의 미한다.

사회인구학적 요인 외에 개인간 요인과 지역사회 요인을 모두 모델에 넣었을 때에도 (Model II) 사회적 연결망, 친목 활동, 여가/레저활동, 지역사회의 안전성, 생활환경, 의료서 비스는 식품의 충분성 및 다양성과 관련된 유의미한 요인이 었다.

다양성이 확보되지 않은 식품충분성을 기준으로 하였을 때 사회인구학적 특성으로 보정한 모델 (Model III)에서 친척, 이웃, 친구와의 연결망이 주 1 회 미만, 친목활동, 여가/레저 활동이 월 1 회 미만, 지역사회의 안전수준, 자연환경, 생활환 경, 대중교통, 의료서비스에 불만족인 대상자들의 식품불충 분성 위험이 유의적으로 증가하였다. 즉, 식품불충분군은 식 품충분 - 비다양군에 비해 사회적 연결망이 미흡하였고 사회 적 활동이 덜 활발하였으며, 지역사회 환경에 대해 덜 만족 한다는 것을 의미한다.

사회인구학적 요인 외에 개인간 요인과 지역사회 요인을 모두 모델에 넣었을 때에도 (Model IV) 친척, 친구와의 사 회적 연결망, 친목활동, 여가/레저활동, 지역사회의 안전성, 생활환경은 식품불충분성과 관련된 유의미한 요인이었다. 즉, 식품불충분군은 식품충분 - 비다양군에 비해 친척, 친구 와의 사회적 연결망이 미흡하였고, 친목활동, 여가/레저활동 
Table 5. Risk for the food sufficiency without variety and food insufficiency according to interpersonal and community factors

\begin{tabular}{|c|c|c|c|c|c|c|c|c|c|c|c|c|}
\hline \multirow{3}{*}{ Variables (Reference) } & \multicolumn{4}{|c|}{ Model I' } & \multicolumn{4}{|c|}{ Model II! } & \multirow{2}{*}{\multicolumn{2}{|c|}{$\begin{array}{c}\text { Model } \mathrm{III}^{2)} \\
\text { Food } \\
\text { insufficiency }\end{array}$}} & \multirow{2}{*}{\multicolumn{2}{|c|}{$\begin{array}{c}\text { Model IV }{ }^{2 I} \\
\text { Food } \\
\text { insufficiency }\end{array}$}} \\
\hline & \multicolumn{2}{|c|}{$\begin{array}{l}\text { Food sufficiency } \\
\text { without variety }\end{array}$} & \multicolumn{2}{|c|}{$\begin{array}{c}\text { Food } \\
\text { insufficiency }\end{array}$} & \multicolumn{2}{|c|}{$\begin{array}{l}\text { Food sufficiency } \\
\text { without variety }\end{array}$} & \multicolumn{2}{|c|}{$\begin{array}{c}\text { Food } \\
\text { insufficiency }\end{array}$} & & & & \\
\hline & $\mathrm{AOR}^{3 !}$ & $95 \% \mathrm{Cl}$ & $\mathrm{AOR}^{3 !}$ & $95 \% \mathrm{Cl}$ & $\mathrm{AOR}^{4 !}$ & $95 \% \mathrm{Cl}$ & $\mathrm{AOR}^{4)}$ & $95 \% \mathrm{Cl}$ & $\mathrm{AOR}^{3 /}$ & $95 \% \mathrm{Cl}$ & $\mathrm{AOR}^{4 \mid}$ & $95 \% \mathrm{Cl}$ \\
\hline \multicolumn{13}{|l|}{ Interpersonal factors } \\
\hline \multicolumn{13}{|l|}{ Social network ( $\geq 1 /$ week) } \\
\hline Relatives (Yes) & $1.30^{51}$ & $(1.26-1.34)$ & 2.16 & $(2.01-2.32)$ & 1.24 & $(1.20-1.28)$ & 1.91 & $(1.77-2.05)$ & 1.60 & $(1.49-1.72)$ & 1.49 & $(1.39-1.61)$ \\
\hline Neighbors (Yes) & 1.22 & $(1.18-1.26)$ & 1.52 & $(1.40-1.64)$ & 1.11 & $(1.08-1.15)$ & 1.18 & $(1.09-1.28)$ & 1.22 & $(1.13-1.32)$ & 1.06 & $(0.97-1.15)$ \\
\hline Friends (Yes) & 1.21 & $(1.18-1.25)$ & 1.58 & $(1.48-1.69)$ & 1.09 & $(1.06-1.13)$ & 1.20 & $(1.12-1.29)$ & 1.26 & $(1.18-1.35)$ & 1.08 & $(1.01-1.16)$ \\
\hline \multicolumn{13}{|l|}{ Social activities ( $\geq 1 /$ month) } \\
\hline Social gathering (Yes) & 1.27 & $(1.23-1.30)$ & 2.06 & $(1.92-2.22)$ & 1.14 & $(1.11-1.18)$ & 1.66 & $(1.54-1.80)$ & 1.57 & $(1.46-1.69)$ & 1.42 & $(1.31-1.53)$ \\
\hline Leisure activity (Yes) & 1.36 & $(1.32-1.41)$ & 2.06 & $(1.86-2.29)$ & 1.25 & $(1.21-1.29)$ & 1.58 & $(1.42-1.76)$ & 1.45 & $(1.31-1.61)$ & 1.23 & $(1.10-1.38)$ \\
\hline Religious activity (Yes) & 1.08 & $(1.04-1.11)$ & 1.02 & $(0.94-1.11)$ & 1.02 & $(0.98-1.05)$ & 0.92 & $(0.84-1.00)$ & 0.95 & $(0.87-1.03)$ & 0.90 & $(0.83-0.98)$ \\
\hline Charity activity (Yes) & 1.37 & $(1.31-1.45)$ & 1.60 & $(1.33-1.92)$ & 1.19 & $(1.13-1.25)$ & 1.13 & $(0.93-1.36)$ & 1.19 & $(0.98-1.44)$ & 0.99 & $(0.82-1.21)$ \\
\hline \multicolumn{13}{|l|}{ Community factors } \\
\hline Safety (Satisfied) & 1.22 & $(1.18-1.26)$ & 1.92 & $(1.77-2.09)$ & 1.09 & $(1.05-1.13)$ & 1.55 & $(1.41-1.70)$ & 1.57 & $(1.44-1.71)$ & 1.45 & $(1.32-1.59)$ \\
\hline Natural environment (Satisfied) & 1.12 & $(1.08-1.16)$ & 1.39 & $(1.28-1.52)$ & 1.00 & $(0.96-1.04)$ & 1.03 & $(0.93-1.13)$ & 1.24 & $(1.14-1.35)$ & 1.02 & $(0.92-1.12)$ \\
\hline Living environment (Satisfied) & 1.27 & $(1.23-1.32)$ & 1.70 & $(1.56-1.86)$ & 1.17 & $(1.13-1.22)$ & 1.32 & $(1.20-1.46)$ & 1.35 & $(1.24-1.47)$ & 1.15 & $(1.04-1.26)$ \\
\hline Public transportation (Satisfied) & 1.09 & $(1.05-1.13)$ & 1.21 & $(1.12-1.31)$ & 0.96 & $(0.92-0.99)$ & 0.93 & $(0.85-1.02)$ & 1.09 & $(1.01-1.19)$ & 0.98 & $(0.89-1.08)$ \\
\hline Health care services (Satisfied) & 1.21 & $(1.17-1.25)$ & 1.35 & $(1.25-1.46)$ & 1.16 & $(1.11-1.20)$ & 1.13 & $(1.03-1.24)$ & 1.09 & $(1.01-1.18)$ & 0.97 & $(0.89-1.07)$ \\
\hline
\end{tabular}

AOR, adjusted odds ratios; $\mathrm{Cl}$, confidence interval.

1) By multinominal logistic regression analysis (baseline: food sufficiency with variety)

2) By binominal logistic regression analysis (baseline: food sufficiency without variety)

3) Adjusted for sociodemographic factors including sex, age group, education level, household income, employment, marital status, and population size of residence

4) Adjusted for sociodemographic factors, interpersonal factors and community factors

5) Bold: $P<0.05$ 
등의 사회적 활동이 덜 활발하였으며, 지역사회의 안전성, 생 활환경에 대해 덜 만족한다는 것을 의미한다. 그러나 종교활 동의 경우 오히려 식품불충분군이 식품충분 - 비다양군에 비 해 활발히 활동하는 것으로 나타났다.

\section{고 찰}

본 연구는 2017년 지역사회건강조사에 참여한 19세 이 상의 한국 성인을 대상으로 식품안정성에 대한 문항 결과를 바탕으로 식품충분 - 다양군, 식품충분 · 비다양군, 식품불충 분군의 세 집단으로 분류한 후, 각 집단의 특성 및 관련 요인 을 파악하고자 수행하였다. 선행연구에서는 경제적인 어려 움으로 인한 식품공급의 부족함을 기준으로 식품안정성과 불 안정성을 구분한 것이 대부분으로, 그동안 식품안정군으로 분류되었지만 다양성을 보장받지 못한 식품충분 - 비다양군 에 대한 연구는 미흡하였다. 본 연구의 조사대상자 중 식품 충분 · 다양군은 $65.3 \%$, 식품충분 · 비다양군은 $31.5 \%$, 식 품불충분군은 $3.2 \%$ 이었다. 지역사회건강조사의 식품안정성 은 조사가 시작된 2008년부터 동일한 문항으로 조사되었으 며, 2011년 원시자료를 본 연구와 동일한 기준으로 분석한 결과 식품충분 - 다양군은 $37.9 \%$, 식품충분 - 비다양군은 $57.4 \%$, 식품불충분군은 $4.7 \%$ 로 나타나 [32], 2011년 이 후 6년 동안 식품충분 - 비다양군과 식품불충분군은 감소하 고 식품충분 · 다양군이 증가한 것을 알 수 있었다.

국내의 식품안정성은 지역사회건강조사 이외에 국민건강 영양조사 및 한국복지패널조사에서도 조사하고 있으나 측정 도구와 용어가 일부 상이하며, 측정도구에 따라 식품불안정 인구 분포도 다르다 [36]. 국민건강영양조사에서는 2005년 부터 지역사회건강조사와 같이 식품안정성을 단일 문항으로 조사하기 시작하였으며, 2012년 국민건강영양조사부터는 미국 식품안정성 서베이 모듈을 기반으로 국내 실정에 맞게 18 문항으로 개발된 한국형 측정도구를 사용하여 추가로 조 사하고 있다 [7]. 2012년 국민건강영양조사 결과 단일문항 의 결과로는 '경제적으로 어려워서 가끔 먹을 것이 부족했음' 이라고 응답한 가구의 분율은 $6.4 \%$, '경제적으로 어려워서 자주 먹을 것이 부족했음'이라고 응답한 가구의 분율은 $1.4 \%$ 이었으나 [37], 18 문항을 바탕으로 분류한 결과로는 $9.3 \%$ 의 가구가 배고픔 미동반 식품불안정가구, $2.0 \%$ 의 가구가 배고픔 동반 식품불안정가구로 분류되었다 [7]. 또한 한국복 지패널조사에서는 18 문항의 한국형 식품보장 측정도구를 6 문항의 간략형 도구로 수정하여 사용하고 있으며, 식품보장/ 식품미보장이라는 용어를 사용하고 있다 [36]. 2013년에 수 집한 한국복지패널 8차 조사자료를 분석한 연구에서 전체 가
구의 식품미보장률은 $2.6 \%$ 이었다 [38]. 식품불안정 가구 또 는 개인의 현황 파악, 식품불안정과 관련된 요인 분석, 또는 식품지원서비스 대상자의 순위 선정 등을 위하여 식품불안 정 가구 또는 개인을 가려내는 것은 매우 중요하며 [39, 40], 식품안정성은 식품의 양적인 충족 뿐 아니라 질적으로 우수 한 다양한 식품의 확보를 포함하고 있으므로 식품의 양적, 질 적 확보를 포함한 식품안정성을 측정할 수 있는 표준화된 도 구와 단일화된 용어를 사용하여 조사하고 발표하는 것이 필 요할 것이다.

본 연구의 식품충분 · 비다양군과 식품불충분군은 식품충 분 - 다양군에 비해 여성, 65세 이상, 중졸 이하, 가구의 월 평균 소득이 200만원 미만, 직업이 없거나 배우자가 없는 경 우, 소규모 지역 거주 등의 특성을 나타냈으며 (Table 1), 이 는 선행연구와 비슷한 결과이었다[6-8]. 지역의 규모별로 살펴보면 식품충분 · 비다양군의 비율은 대규모 $28.3 \%$, 중 규모 $30.5 \%$, 소규모 $34.2 \%$, 극소규모 $38.5 \%$ 순으로 지역 의 규모가 작을수록 식품충분 - 비다양군의 비율이 높았다 (Fig. 1). 식품불충분군의 비율도 대규모 지역은 $2.5 \%$ 이고 극소규모 지역은 $4.3 \%$ 로 약 1.6 배의 차이를 보였다. 이는 식품불안정군은 인구가 많은 도시 지역에 비해 농촌지역의 비율이 높았다는 국내외 결과와 유사한 결과였다 [8, 41].

건강행동 중 금연, 규칙적 운동, 적절한 수면 실천 비율은 식품충분 - 다양군이 가장 높았으나, 금주 실천 비율과 아침 식사 실천 비율은 식품불충분군이 가장 높았다. 2010 2012 년 국민건강영양조사 결과를 분석한 선행 연구에서는 식품 불안정군이 식품안정군에 비해 금주 실천 비율은 높았으나 아침식사 실천 비율은 낮았던 것으로 보고되었다 [11].

고혈압, 당뇨, 이상지질혈증 및 관절염 비율은 식품충분 다양군에 비해 식품충분 · 비다양군과 식품불충분군이 높게 나타났다. 다만 과체중 이상은 식품충분 - 다양군이 가장 높 은 결과를 보였는데, 이는 식품불안정군이 식품안정군에 비 해 비만율이 높다는 외국의 결과와는 차이가 있었다 [42]. 2011년 지역사회건강조사 결과를 분석한 연구에서는 남성 의 경우에는 식품불안정군이 식품안정군에 비해 과체중 이 상의 비율이 낮았으나, 여성의 경우 과체중 이상의 비율이 높 아, 성별 차이를 나타냈다 [9]. 본 연구에서 65세 이상의 비 율이 식품충분 · 다양군에서는 $13.2 \%$, 식품충분 · 비다양군 에서는 $23.6 \%$, 식품불충분군에서는 $46.0 \%$ 로, 식품불충분 군에는 65 세 이상의 노인 비율이 높았다. 한국인의 경우 65 세 이후에는 연령이 증가할수록 체중과 $\mathrm{BMI}$ 가 감소하고, 과 체중율과 비만율도 감소한 것으로 보고되어 [43], 식품불충 분군에서 비만율이 낮은 것과 관련된 것으로 보인다. 따라서 성인과 노인을 구분하여 분석할 필요가 있을 것으로 생각된다. 
본 연구에서 사회적 연결망 (친척, 이웃, 친구) 중 주 1 회 이상의 친척과 친구 관계는 식품충분 - 다양군이 가장 높은 비율을 보였고, 이웃과의 관계는 식품불충분군이 가장 높은 비율이었다 (Table 3). 그러나 사회인구학적 특성으로 보정 한 후에는 친척, 이웃, 친구와의 연결망이 주 1 회 미만인 대 상자들이 식품충분 · 다양군에 비해 식품충분 · 비다양군과 식품불충분군일 위험이 더 높았다 (Table 5). 사회인구학적 특성, 개인간 요인, 지역사회 요인을 모두 고려한 후에도 친 척과의 연결망은 교차비가 가장 높아 매우 중요한 요인임을 알 수 있었다. 사회적 활동은 종교활동을 제외한 모든 활동 에서 식품충분 - 다양군이 가장 높은 비율을 보였고, 가장 활 발한 활동으로는 친목활동이었다 (Table 3). 다른 요인들로 보정한 후에도 식품충분 - 비다양군은 식품충분 - 다양군에 비해, 식품불충분군은 식품충분 · 다양군과 식품충분 · 비다 양군에 비해 친목활동, 여가/레저활동이 덜 활발하였으나, 종 교활동의 경우 식품불충분군이 식품충분 · 비다양군에 비해 활발한 것으로 나타났다 (Table 5).

식품안정성과 사회적 연결망에 대한 국내 연구에서는 축 적된 복지패널을 활용하여 취약가구를 대상으로 식품안정성 에 영향을 주는 요인을 분석한 결과 가족관계와 사회적 친분 관계의 만족도가 식품안정성에 긍정적인 영향을 주는 변수 임을 확인하였다 [44]. 외국의 연구로는 이웃과의 연결망과 신뢰가 식품안정성 확보에 긍정적인 영향을 주었고 [18], 식 품불안정을 경험한 사람들이 가족, 이웃, 친구 등과의 교류 와 지지, 종교활동 참여 등으로 식품불안정을 극복할 수 있 었다는 결과가 보고되어 [45], 사회적 연결망과 사회적 활동 등의 개인간 요인이 식품안정성과 관련이 있다는 본 연구 결 과와 일치하였다.

또한 본 연구에서 안전수준, 자연환경, 생활환경, 대중교 통, 의료서비스 등의 사회물리적 환경에 만족하지 못하는 대 상자들이 식품충분 · 비다양성이나 식품불충분성의 위험이 증가하는 것으로 나타나 지역사회의 환경이 식품충분성 및 다양성과 관련된 요인임을 알 수 있었다. 특히, 여러 요인으 로 보정한 모델 (Model II)에서는 안전한 환경, 생활환경, 의 료서비스 등에 만족하지 못하는 대상자들의 식품충분 · 비다 양성과 식품불충분성의 위험이 증가하였다. 선행연구에서는 걷기에 좋은 환경과 편리한 교통이 식품안정성과 관련된다 고 하였다 [19, 45].

이와 같이 현재 국민건강영양조사 결과에서 식품안정군으 로 분류되는 식품충분 · 비다양군은 사회인구학적 요인, 친척 이나 친구와의 사회적 관계망, 친목활동이나 여가/레저활동, 지역의 안전수준과 생활환경에 대해 식품불충분군 뿐만 아 니라 식품충분 - 다양군과도 유의한 차이를 나타냈으므로, 향
후 다양한 식품안정 프로그램이나 정책에서 식품충분 · 비다 양군에 대한 고려가 필요할 것으로 생각된다.

현재 국내에서 식품불안정 해소를 위한 저소득층 식생활 지원은 식사나 식품을 현물로 제공하는 개인차원의 공급이 대부분인데, 일률적 지원으로 대상자의 건강상태나 식품 선 호도가 반영되기 어려워 효율성이 떨어질 수 있다는 지적이 있었고, 혼자 섭취해야 하는 불만도 있었다 [46]. 반면 서울 시의 어르신 영양꾸러미 프로그램은 맞춤형 식품패키지 제 공뿐만 아니라 집합 영양교육과 방문상담을 통해 지역사회 내에서 사회적 연결망과 활동을 촉진시켜 참여자의 건강상 태, 영양소 섭취수준 및 식품안정성 확보율을 증가시킬 수 있 었다 [47]. 따라서 식품불안정성을 개선하기 위해서는 식품 의 공급뿐만 아니라 이웃과의 교류를 촉진할 수 있는 사회 활 동 프로그램과 지역사회의 환경개선이 도움이 될 것이라고 생각된다.

본 연구는 지역사회건강조사 자료를 이용한 횡단연구이기 에 식품충분성 및 다양성을 고려한 식품안정성과 개인적 요 인, 개인간 요인 및 지역사회 요인에 관한 인과관계를 명확히 해석할 수 없다는 제한점을 가지고 있다. 또한, 식품충분 · 다 양성을 측정하기 위해 가구의 식생활 형편을 묻는 단일문항 을 사용하였기에 식품의 유용성 (availabiliy), 접근성 (accessibility), 이용성 (utilization), 시간의 흐름과 상관 없는 지속적 안정성 (stability) 등의 다양한 측면을 고려하 기 어려웠고 [48], 식품섭취조사가 이루어지지 않아 다양성 을 실제 섭취하는 식품 기반으로 측정하지 못하였다. 또한 지 역사회건강조사는 $1: 1$ 면접조사 방식으로 신장, 체중이나 질 환 유무 등 건강관련 문항에 대한 응답이 자가 보고되었기 때 문에 오차를 나타낼 수 있는 가능성이 있으므로, 신체계측과 임상조사 및 식품섭취조사를 수행하는 다른 표본조사와의 통 합적인 후속연구가 필요하다고 생각된다.

그럼에도 불구하고 본 연구는 국내의 대표성 있는 자료를 바탕으로 다양하고 충분한 식품확보를 고려한 식품안정성의 분포와 인구사회학적 특성, 건강관련 특성을 파악하고 개인 간 요인및 지역사회 요인과의 유의한 관련성을 규명하였다 는 점에서 의의가 있다. 식품의 안정성은 유용성, 접근성, 이 용성, 안정성의 4 가지 개념을 포함한 것으로 소득수준 뿐 아 니라 사회적 연결망, 사회적 활동, 사회물리적 환경 등이 영 향을 줄 수 있는 중요한 요인임을 알 수 있었다. 따라서 다양 성과 충분성이 확보되지 못한 식품불안정과 관련된 문제를 해결하기 위해서는 식품을 지원하는 정책 뿐 아니라 사회적 연결망을 유지하고 친목활동 등 사회적 활동을 촉진시킬 수 있는 중재활동과 지역사회 환경을 개선하는 정책이 함께 필 요할 것으로 사료된다. 


\section{요 약}

본 연구에서는 질병관리본부의 2017년 지역사회건강조사 에 참여한 19 세 이상의 한국 성인 228,310명을 대상으로, 식품의 충분한 공급과 다양성 확보를 기준으로 식품충분 . 다양군, 식품충분 - 비다양군, 식품불충분군으로 분류한 집 단의 개인적 요인, 개인간 요인, 지역사회 요인에 차이가 있 는지를 파악하고, 식품충분성 및 다양성과 관련된 개인간 요 인과 지역사회 요인을 파악하고자 하였다. 본 연구의 대상자 중 식품충분 · 다양군은 $65.3 \%$, 식품충분 · 비다양군은 $31.5 \%$, 식품불충분군은 $3.2 \%$ 이었다.

식품충분 · 비다양군과 식품불충분군은 식품충분 · 다양군 에 비해 여성, 65 세 이상, 중졸 이하, 가구의 월평균 소득이 200만원 미만, 직업이 없거나 배우자 없는 경우, 소규모 지 역 거주 등의 특성을 나타냈으며, 모든 건강행동과 건강상태 에서 집단별 분포에 유의적인 차이가 있었다. 건강행동 중 금 연, 규칙적 운동, 적절한 수면 실천 비율은 식품충분 · 다양 군이 가장 높았으나, 금주와 규칙적 아침식사 실천 비율은 식 품불충분군이 가장 높았다. 고혈압, 당뇨, 이상지질혈증 및 관절염 비율은 식품충분 · 다양군에 비해 식품충분 · 비다양 군과 식품불충분군이 높게 나타났으나, 과체중 이상은 식품 충분 · 다양군이 가장 높은 결과를 보였다. 또한 식품충분 . 비다양군은 규칙적인 아침식사를 제외한 모든 요인에서 식 품충분 - 다양군과 차이가 있었으며, 대중교통과 의료서비스 를 제외한 모든 요인에서 식품불충분군과 차이가 있었다.

식품충분성 및 다양성과 관련된 개인간 요인과 지역사회 요인을 파악하기 위해 사회인구학적 요인, 개인간 요인, 지 역사회 요인을 모두 고려하여 다변량로지스틱 회귀분석을 실 시한 결과 식품충분 · 다양군에 비해 식품충분 · 비다양군과 식품불충분군에서는 사회적 연결망이 미흡하고, 사회적 활 동이 활발하지 않았으며, 안전한 환경, 생활환경, 의료서비스 등에 대하여 불만족하였다. 본 연구에서는 지역사회건강조 사 또는 국민건강영양조사에서 식품안정군으로 분류되지만 다양성을 확보하지 못한 군을 분류하여 분석하였고, 그 결과 식품충분 - 비다양군은 식품불충분군 뿐 아니라 식품충분 다양군과도 개인적 요인, 개인간 요인, 지역사회 요인에서 유 의적인 차이가 있었다. 이와 같이 사회인구학적 특성, 건강 행동, 건강상태 등의 개인적 요인과 사회적 연결망, 사회적 활동 등의 개인간 요인, 그리고 지역사회 환경 등이 식품충 분성 및 다양성과 관련된 요인으로 규명되어, 식품불안정과 관련된 문제를 해결하기 위해서는 식품의 다양한 공급을 고 려한 식품지원 정책과 더불어 사회적 연결망과 사회적 활동
을 촉진시킬 수 있는 다양한 영양교육 프로그램 개발 등이 지 역사회의 환경 개선 정책과 함께 이루어져야 할 것으로 생각 된다.

\section{ORCID}

Jiyoun Hong: https://orcid.org/0000-0001-5379-7875

Taisun Hyun: https://orcid.org/0000-0002-6888-1612

\section{References}

1. United States Department of Agriculture Economic Research Service. Food security in the US: Measurement [Internet]. United States Department of Agriculture; 2020 [cited 2020 Oct 8]. Available from: https://www.ers.usda.gov/topics/food-nutritionassistance/food-security-in-the-us/measurement/.

2. Gundersen C, Ziliak JP. Food insecurity and health outcomes. Health Aff 2015; 34(11): 1830-1839.

3. Murthy VH. Food insecurity: A public health issue. Public Health Rep 2016; 131(5): 655-657.

4. Ministry of Health and Welfare. The 4th Health Plan (20162020) [Internet]. Ministry of Health and Welfare; 2015 [cited 2020 Sep 14]. Available from: http://www.mohw.go.kr/react/jb/ sjb030301vw.jsp?PAR_MENU_ID=03\&MENU_ID $=0319 \& C O N T$ _SEQ=330479.

5. Ministry of Health and Welfare, Korea Disease Control and Prevention Agency. Korea Health Statistics 2017: Korea National Health and Nutrition Examination Survey (KNHANES VII-2). Sejong: Ministry of Health and Welfare; 2018.

6. Kim K, Kim MK, Shin YJ, Lee SS. Factors related to household food insecurity in the Republic of Korea. Public Health Nutr 2011; 14(6): 1080-1087.

7. Kim HJ, Oh K. Household food insecurity and dietary intake in Korea: results from the 2012 Korea National Health and Nutrition Examination Survey. Public Health Nutr 2015; 18(18): 3317-3325.

8. Park J, Kang G, Tak Y, Chang S, Lee K, Kim H. The influence of community characteristics on food insecurity Korean adults. Health Policy Manag 2016; 26(3): 226-232.

9. Chun IA, Ryu SY, Park J, Ro HK, Han MA. Associations between food insecurity and healthy behaviors among Korean adults. Nutr Res Pract 2015; 9(4): 425-432.

10. Kim JE, Tsoh JY. Cigarette smoking among socioeconomically disadvantaged young adults in association with food insecurity and other factors. Prev Chronic Dis 2016; 13(E08): 1-10.

11. Lee SE, Song YJ, Kim Y, Choe J, Paik HY. Household food insufficiency is associated with dietary intake in Korean adults. Public Health Nutr 2016; 19(6): 1112-1121.

12. Laraia BA. Food insecurity and chronic disease. Adv Nutr 2013; 4(2): 203-212.

13. Gucciardi E. Vahabi M, Norris N, Del Monte JP, Farnum C. The intersection between food insecurity and diabetes: a review. Curr Nutr Rep 2014; 3(4): 324-332. 
14. Ford ES. Food security and cardiovascular disease risk among adults in the United States: findings from the National Health and Nutrition Examination Survey, 2003-2008. Prev Chronic Dis 2013; 10: E202.

15. Mendy VL, Vargas R, Cannon-Smith G, Payton M, Enkhmaa B, Zhang L. Food insecurity and cardiovascular disease risk factors among Mississippi adults. Int J Environ Res Public Health 2018; 15(9): 2016-2023.

16. Arenas DJ, Thomas A, Wang J, DeLisser HM. A systematic review and meta-analysis of depression, anxiety, and sleep disorders in US adults with food insecurity. J Gen Intern Med 2019; 34(12): 2874-2882.

17. Yang YJ. Socio-demographic characteristics, nutrient intakes and mental health status of older Korean adults depending on household food security: based on the 2008-2010 Korea National Health and Nutrition Examination Survey. Korean J Community Nutr 2015;20(1): 30-40.

18. Martin KS, Rogers BL, Cook JT, Joseph HM. Social capital is associated with decreased risk of hunger. Soc Sci Med 2004; 58(12): 2645-2654.

19. Chung WT, Gallo WT, Giunta N, Canavan ME, Parikh NS, Fahs MC. Linking neighborhood characteristics to food insecurity in older adults: the role of perceived safety, social cohesion, and walkability. J Urban Health 2012; 89(3): 407-418.

20. Schroeder K, Smaldone A. Food insecurity: a concept analysis. Nurs Forum 2015; 50(4): 274-284.

21. Peng W, Dernini S, Berry EM. Coping with food insecurity using the sociotype ecological framework. Front Nutr 2018; 5: 107.

22. McLeroy KR, Bibeau D, Steckler A, Glanz K. An ecological perspective on health promotion programs. Health Educ Q 1988; 15(4): 351-377.

23. Story M, Neumark-Sztainer D, French S. Individual and environmental influences on adolescent eating behaviors. J Am Diet Assoc 2002; 102(3): S40-S51.

24. Shim JS, Oh K, Nam CM. Association of household food security with dietary intake: based on the Third (2005) Korea National Health and Nutrition Examination Survey (KNHANES III). Korean J Nutr 2008; 41(2): 174-183.

25. Park GA, Kim SH, Kim SJ, Yang YJ. Health and nutritional status of Korean adults according to age and household food security: Using the data from 2010 2012 Korea National Health and Nutrition Examination Survey. J Nutr Health 2017; 50(6): 603-614.

26. Bae A, Yoon JH, Yun SY, Asano K. Dietary and health characteristics of the young-old and the old-old by food security status: analysis of data from the 6th (2013 2015) Korea National Health and Nutrition Examination Survey. J Nutr Health 2019; 52(1): 104-117.

27. Randall E, Nichaman MZ, Contant CF Jr. Diet diversity and nutrient intake. J Am Diet Assoc 1985; 85(7): 830-836.

28. Vecchia CL, Munoz SE, Braga C, Fernandes E, Decarli A. Diet diversity and gastric cancer. Int J Cancer 1997; 72(2): 255-257.

29. Fernandez E, Negri E, La Vecchia C, Franceschi S. Diet diversity and colorectal cancer. Prev Med 2000; 31(1): 11-14.

30. Garavello W, Giordano L, Bosetti C, Talamini R, Negri E, Tavani A et al. Diet diversity and the risk of oral and pharyngeal cancer. Eur J Nutr 2008; 47(5): 280-284.

31. Kant AK, Schatzkin A, Harris TB, Zeigler RG, Block G. Dietary diversity and subsequent mortality in the first national health and nutritional examination survey epidemiologic follow-up study. Am J Clin Nutr 1993; 57(3): 434-440.

32. Ministry of Health and Welfare. Government enacted National Common Dietary Guidelines for healthy dietary life [Internet]. Ministry of Health and Welfare; 2016 [cited 2020 Sep 14]. Available from: http://www.mohw.go.kr/react/al/sal0301vw.jsp?PAR _MENU_ID=04\&MENU_ID=0403\&CONT_SEQ=330959.

33. Korea Disease Control and Prevention Agency. Community Health Survey [Internet]. Korea Disease Control and Prevention Agency; 2019 [cited 2020 Sep 12]. Available from: https:// chs.cdc.go.kr/chs/.

34. World Health Organization, Western Pacific Region. The AsiaPacific perspective: redefining obesity and its treatment. Sydney: Health Communications Australia Pty Limited; 2000.

35. Lee JH. The regional health inequity, and individual and neighborhood level health determinants. Health Soc Welf Rev 2016;36(2): 345-384.

36. Choi SK, Kim SA, Lee J. Exploring impacts of food insecurity on health and strategies to manage adverse health outcomes among food insecure populations [Internet]. Korea Institute for Health and Social Affairs; 2019 [cited 2020 Sep 15]. Available from: https:/www.kihasa.re.kr/web/publication/research/view.do?page Index $=6 \&$ keyField $=\&$ key $=\&$ menuId $=44 \&$ tid $=71 \&$ bid $=12 \&$ divisio $\mathrm{n}=001$ \&ano $=2506$.

37. Ministry of Health and Welfare, Korea Disease Control and Prevention Agency. Korea Health Statistics 2012: Korea National Health and Nutrition Examination Survey (KNHANES VII-2). Sejong: Ministry of Health and Welfare; 2013.

38. Lee H, Kim WJ. Factors associated with food insecurity among one-person households. Health Soc Welf Rev 2015; 35(3): 453484.

39. Gundersen C, Engelhard EE, Crumbaugh AS, Seligman HK. Brief assessment of food insecurity accurately identifies high-risk US adults. Public Health Nutr 2017; 20(8): 1367-1371.

40. Vaudin, A., Simon, J., \& Sahyoun, N. Developing the expanded food security screener and pilot testing it for prioritization of applicants to the home-delivered meal program. Top Clin Nutr 2020;35(1): 19-27.

41. Dean WR, Sharkey JR. Food insecurity, social capital and perceived personal disparity in a predominantly rural region of Texas: an individual-level analysis. Soc Sci Med 2011; 72(9): 1454-1462.

42. Pan L, Sherry B, Njai R, Blanck HM. Food insecurity is associated with obesity among US adults in 12 states. J Acad Nutr Diet 2012; 112(9): 1403-1409.

43. Son IH, Han YH, Hyun T. Changes in weight, waist circumference, prevalence of obesity, and dietary factors associated with weight gain over 8 years in Korean adults: Longitudinal data from the Korean Genome and Epidemiology Study. J Nutr Health 2017; 50(4): 336-349.

44. Kim W, Yang SR. A study on food security of vulnerable households. Korean J Agric Manag Policy 2017; 44(3): 236-256.

45. De Marco M, Thorburn S, Kue J. "In a country as affluent as 
America, people should be eating": Experiences with and perceptions of food insecurity among rural and urban Oregonians. Qual Health Res 2009; 19(7): 1010-1024.

46. Hwang J, Kim B, Kim K. A qualitative study on attitude, acceptability, and adaptation for home-delivered meal services in the Korean elderly from the perspective of life context. Korean J Community Nutr 2014; 19(5): 459-467.

47. Lee Y, Yang N, Shin M, Lee K, Yoo CH, Kim K. The effects of a personalized nutrition intervention program on food security, health and nutritional status of low-income older adults in Seoul city. J Nutr Health 2020; 53(4): 416-430.

48. Food and Agriculture Organization. An introduction to the basic concepts of food security [Internet]. Food and Agriculture Organization; 2018 [cited 2020 Oct 19]. Available from: http:// www.fao.org/3/a-al936e.pdf. 